\title{
Editorial
}

\section{Cytomegalovirus Disease of the Upper Gastrointestinal Tract: An Emerging Infection in Immunocompetent Hosts}

\author{
Elisa Gravito-Soares Nuno Almeida \\ Gastroenterology Department, Coimbra University Hospital, Coimbra, Portugal
}

\section{Keywords}

Cytomegalovirus · Upper gastrointestinal tract · Immunocompetent hosts

\section{Doença por citomegalovírus do trato gastrointestinal alto: uma infeção emergente em hospedeiros imunocompetentes}

\section{Palavras Chave \\ Citomegalovírus - Trato gastrointestinal alto · Hospedeiros imunocompetentes}

Cytomegalovirus (CMV) is a DNA virus belonging to the Herpesviridae family with a high seroprevalence in the general population (40-100\%) [1-4]. Acute primary CMV infection usually occurs during childhood and early adolescence and has a benign course. After resolution of the acute phase, the virus remains inactive in the host (latent phase), maintaining the viral genome in the absence of production of lytic infectious virions $[1,4,5]$. The impairment of host immune response can cause CMV disease as a result of endogenous reactivation or exogenous reinfection. Generally, this condition arises in immunocompromised patients, such as those with AIDS,

\begin{tabular}{|c|c|}
\hline$A D C$ & iedade Portuguesa de $\mathrm{C}$ \\
\hline 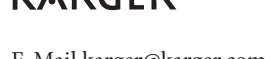 & $\begin{array}{l}\text { Karger } \\
\text { Open access }\end{array}$ \\
\hline wwy & $\begin{array}{l}\text { This article is licensed under the Creative Commons Attribution- } \\
\text { NonCommercial-NoDerivatives } 4.0 \text { International License (CC BY- } \\
\text { NC-ND) (http://www.karger.com/Services/OpenAccessLicense). } \\
\text { Usage and distribution for commercial purposes as well as any dis- } \\
\text { tribution of modified material requires written permission. }\end{array}$ \\
\hline
\end{tabular}

organ transplantation, and active malignancy undergoing chemotherapy $[1-4,6-9]$.

Gastrointestinal involvement by CMV is common. Endoscopic findings are nonspecific, with mucosal ulceration being the most common $[1,7,10]$. The gold standard in CMV disease diagnosis is histopathology of the involved organ, with high sensitivity in both early and late phases. Histological findings include typical intranuclear inclusions or positive immunohistochemical staining for CMV $[1,2,11]$. Regarding the management of CMV gastrointestinal disease, ganciclovir is recommended as the first choice, despite the potential for hematological toxicity, central nervous system disorders, hepatotoxicity, irreversible infertility, and teratogenesis. In patients with normal renal function, intravenous ganciclovir $5 \mathrm{mg} / \mathrm{kg}$ twice daily or oral valganciclovir $900 \mathrm{mg}$ twice daily should be used for 2-3 weeks. Available alternative therapies, such as foscarnet, also had nonnegligible toxicity including nephrotoxicity and hydroelectrolytic disturbances. Additionally, the widespread use of these drugs may lead to the emergence of resistant viral strains. The length of treatment is determined by once weekly monitoring of CMV viral loads. A longer period of time is usually required for gastrointestinal tissue-invasive disease. Maintenance therapy (oral valganciclovir $900 \mathrm{mg}$ once daily) is reserved for CMV gastrointestinal disease relapse, after a reinduction regimen $[3,6,9]$. In immunocompromised

Dr. Elisa Gravito-Soares

Gastroenterology Department, Coimbra University Hospital Praceta Prof. Mota Pinto

PT-3000-075 Coimbra (Portugal)

E-Mail es18497@gmail.com 
patients, prophylaxis with oral valganciclovir is advocated in HIV-infected patients with a CD $4+$ count $<50 / \mathrm{mm}^{3}$ and $\mathrm{CMV}$-negative recipients receiving an organ from CMV-positive donors $[6,10]$. Despite a well-established approach in immunocompromised patients, no clear guidelines have been proposed for immunocompetent patients $[2,6,9]$.

According to the host immune system, CMV disease can assume distinct clinical features, with variable severity and extent along the gastrointestinal tract. In immunocompromised patients, the colon is the main involved site and is associated with a high morbidity and mortality. In immunocompetent patients, CMV disease is rare even when viral shedding occurs, because cell-mediated host immune response (CD8+ cytotoxic $\mathrm{T}$ lymphocytes and memory T cells) prevents the development of overt CMV disease $[2,5]$. However, in the last decades, CMV disease in immunocompetent patients has been increasing, with more involvement of the upper gastrointestinal tract [2, $7,8,10,12]$. Critically ill patients, particularly those with sepsis and under mechanical ventilation, have been proposed as being at risk for this increasing incidence because of a transiently suppressed immunity $[5,13]$. Further, some cases in healthy individuals have also been reported $[2,11,12,14,15]$. Despite uncertainties about the burden of CMV disease in these patients due to few reported cases, morbidity and mortality seem to be lower than in immunocompromised patients. However, lifethreating situations have been described, especially in elderly patients and those with associated critical illnesses/ comorbidities $[3,5,12-14,16]$.

Marques et al. [17] published in this issue of GE - Portuguese Journal of Gastroenterology a paper which describes the clinical and endoscopic features, as well as the therapy and outcome, of a CMV disease case series with involvement of the upper gastrointestinal tract. During 10 years, they retrospectively included 12 cases of histopathologically confirmed upper gastrointestinal CMV disease, 5 esophagitis and 7 gastritis. Most patients were symptomatic and showed mucosal ulceration at endoscopy. CMV disease was disseminated in $25 \%$ of patients (all immunocompromised). The majority of patients underwent antiviral therapy with ganciclovir/valganciclovir (92\%), with a 1 -year mortality of $25 \%$. Twenty-five percent of patients were immunocompetent (mean age $75 \pm 20$ vs. $57 \pm 16$ years), without disseminated disease, and 1 patient died without starting timely antiviral therapy. The authors concluded that early diagnosis and adequate antiviral treatment are essential in the approach to upper gastrointestinal CMV, due to its association with significant mortality.
The major clinical challenge remains the optimization of early diagnosis and better understanding of the clinical course of CMV disease in immunocompetent patients, selecting those who will need antiviral therapy. The recognition of gastrointestinal CMV disease in these patients is difficult due to a low index of clinical suspicion in relation with low reported incidence, broad tissue tropism by $\mathrm{CMV}$, nonspecific presenting symptoms, and the possibility of the disease mimicking other clinical conditions. Thus, a low threshold for performing endoscopic examination is crucial to early diagnosis of this condition. Several studies demonstrated that advanced age is a risk factor for CMV disease in immunocompetent patients, in line with immune senescence $[2,3,8,18]$. In addition, critical conditions or comorbidities can play a role in patients without immunodeficiency or immunosuppression, causing significant impairment of host immune response $[2,3,5,8,13,18]$. Marques et al. [17] also reported advanced age and those conditions in all immunocompetent patients. Concerning therapeutic initiation and outcome of CMV disease in immunocompetent patients, a considerable morbidity and mortality have been reported, especially in elderly patients and those with comorbidities/critical illnesses. However, not all patients received antiviral therapy (24-70\%), with few cases of worse outcome in patients without therapy $(0-32 \%)$ [2, $3]$. Therefore, the role of antiviral therapy in the immunocompetent setting remains to be established. In the absence of risk factors, antiviral therapy appears to have little benefit, since most untreated cases have self-limited disease resolving without sequelae $[15,19]$.

The study published in this issue of GE underlines the paramount importance of early diagnosis and targeted treatment of upper gastrointestinal CMV disease, which implies a high index of clinical suspicion, even in immunocompetent patients. In the immunocompetent context, clinical judgment should still be used to determine which patients should undergo antiviral therapy, weighing the benefits against potential toxicity. Current limited evidence suggests that antiviral therapy is appropriate for immunocompetent patients with clinical risk factors, such as severe CMV disease, advanced age, and presence of critical illnesses or immunomodulatory comorbidities.

\section{Disclosure Statement}

The authors have no conflicts of interest to declare. DOI: $10.1159 / 000479974$
Gravito-Soares/Almeida 


\section{References}

1 You DM, Johnson MD: Cytomegalovirus infection and the gastrointestinal tract. Curr Gastroenterol Rep 2012;14:334-342.

2 Bernard S, Germi R, Lupo J, et al: Symptomatic cytomegalovirus gastrointestinal infection with positive quantitative real-time PCR findings in apparently immunocompetent patients: a case series. Clin Microbiol Infect 2015;21:1121.e1-e7.

3 Rafailidis PI, Mourtzoukou EG, Varobitis IC, et al: Severe cytomegalovirus infection in apparently immunocompetent patients: a systematic review. Virol J 2008;5:47.

4 Lancini D, Faddy HM, Flower R, et al: Cytomegalovirus disease in immunocompetent adults. Med J Aust 2014;201:578-580.

5 Al-Omari A, Aljamaan F, Alhazzani W, et al: Cytomegalovirus infection in immunocompetent critically ill adults: literature review. Ann Intensive Care 2016;6:110.

6 Kotton CN, Kumar D, Caliendo AM, et al: Updated international consensus guidelines on the management of cytomegalovirus in solid organ transplantation. Transplantation 2013;96:333-360.

7 Iwamuro M, Kondo E, Tanaka T, et al: Endoscopic manifestations and clinical characteristics of cytomegalovirus infection in the upper gastrointestinal tract. Acta Med Okayama 2017;71:97-104.
8 Maiorana A, Baccarini P, Foroni M, et al: $\mathrm{Hu}$ man cytomegalovirus infection of the gastrointestinal tract in apparently immunocompetent patients. Hum Pathol 2003;34:13311336.

9 Benson CA, Kaplan JE, Masur H, et al: Treating opportunistic infections among HIV-infected adults and adolescents: recommendations from CDC, the National Institutes of Health, and the HIV Medicine Association/Infectious Diseases Society of America. MMWR Recomm Rep 2004;53:1-112.

10 Nasa M, Sharma Z, Sud R, et al: Cytomegalovirus infection of gastrointestinal tract. Community Acquir Infect 2016;3:4-9.

11 Ebisutani C, Kawamura A, Shibata N, et al: Gastric ulcer associated with cytomegalovirus in an immunocompetent patient: method for diagnosis. Case Rep Gastroenterol 2012;6: 365-368.

12 Almeida N, Romãozinho JM, Amaro P, et al: Fatal mid-gastrointestinal bleeding by cytomegalovirus enteritis in an immunocompetent patient. Acta Gastroenterol Belg 2009;72: 245-248
13 Frantzeskaki FG, Karampi ES, Kottaridi C: Cytomegalovirus reactivation in a general, nonimmunosuppressed intensive care unit population: incidence, risk factors, associations with organ dysfunction, and inflammatory biomarkers. J Crit Care 2015;30:276-281.

14 Krajicek E, Shivashankar R, Hansel S: Cytomegalovirus and the seemingly immunocompetent host: a case of a perforating gastric ulcer. ACG Case Rep J 2017;4:e27.

15 Fyock C, Gaitanis M, Gao J, et al: Gastrointestinal CMV in an elderly, immunocompetent patient. R I Med J (2013) 2014;97:53-56.

16 Shen L, Youssef D, Abu-Abed S, et al: Cytomegalovirus duodenitis associated with lifethreatening duodenal haemorrhage in an immunocompetent patient: a case report. Int J Surg Case Rep 2017;33:102-106.

17 Marques S, Carmo J, Pinto D, et al: Cytomegalovirus disease of the upper gastrointestinal tract: a 10-year retrospective study. GE Port J Gastroenterol DOI: 10.1159/000479232.

18 Nikolich-Zugich J, van Lier R: Cytomegalovirus (CMV) research in immune senescence comes of age: overview of the 6th International Workshop on CMV and Immunosenescence. Geroscience 2017;39:245-249.

19 Kastenbauer U, Ließ H, Kremer M: CMV-associated gastric ulcer in an immunocompetent male patient (in German). Internist (Berl) 2016;57:724-727.
Upper Gastrointestinal CMV Disease in Immunocompetent Hosts
GE Port J Gastroenterol 2017;24:259-261

DOI: $10.1159 / 000479974$ 